\section{Growing analysis}

\section{Bernard Wood}

Size and Scaling in Primate Biology.

Edited by William L. Jungers.

Plenum: 1985. Pp.491. \$69.50, 666 .

THIS book is about allometry, which, in both the literal and the metaphorical sense, is a growth area. Literally, because it is the study of the effects of an increase in the size of organisms on their shape. Metaphorically, because in recent years allometry has taken over from multivariate morphometrics as one of the main analytical preoccupations of primatologists and hominid palaeontologists.

A system is allometric when a variable (or variables) measuring overall size has more than a random effect on another measure, be it tooth size, gut area or limb length to name but a few of the associations discussed in the book. Various contributors try to classify allometric studies, but they can be broadly divided into three categories. The first, which I shall call "organism-based", and which includes ontogenetic and intraspecific allometry, deals with the effect of size on the shape of an organism while holding functional and ecological variables partly, or wholly, constant. The second category is "systembased". In this approach groups of organisms are used as tools to investigate the influence of size on function and ecological context. Such studies are usually broad and interspecific, and include the analysis of grade shifts; that is, changes in the intercept as well as differences in the slopes. Research of the third category makes use of the empirical observation that variables are correlated to predict one variable from another. Often this stands on its head the notion of a "dependent" and an "independent" variable, for what is usually regarded as independent (body size, for example) is often predicted from dependent variables such as tooth size. This final method is applied most often in palaeontological studies which are perforce based on fragmentary material and may use ontogenetic, intraspecific or interspecific associations.

The twin aims of the book are to assess past progress in allometric work and to review the future prospects. Several of the contributors discuss the role of allometry in evolutionary change. Is evolution simply the transposition of the derived form to a position up or down the ontogenetic slope (Shea; Cochard), or is it more than one process - perhaps "short term", involving relatively simple adjustments of growth, and "long term", involving adjustments of function and grade, and perhaps dictated by general metabolic constraints (Martin and Harvey; Ford and Corruccini)? Although not always in agreement with him, I especially enjoyed Shea's contribution. His work on ontogenetic allometry is stimulating, but even though my prejudices about the pattern of hominid evolution are reinforced by the findings of his excursion into that minefield, I remain unconvinced that ontogenetic allometry "explains" all evolutionary change. Lande provides a much needed genetic perspective on allometry, and Leutenegger and Cheverud's account of the effect of size on sexual dimorphism in primates is both an analytically ingenious and intellectually rigorous attempt to understand the mechanism of the strong positive allometry that is seen in sexually dimorphic species.

A number of the chapters provide overviews of particular systems - Martin et al. on the gut, Jungers on the skeleton, Larson on organ weights, and Gingerich and Smith on dentition. Hidden within the latter is an admirably concise discussion of the vexed question of line-fitting. This is a point which is addressed by several of the contributors (Martin et al.; Wolpoff; Steudel and Ford; Corruccini). Wolpoff takes an admirable, but misguided, swim against the tide of consensus. The majority vote of the contributors is against him. Least squares regression is a technique best reserved for prediction, with association being best studied by the major axis technique, or by one of its variations. Smith and Steudel each address the problem of using apparent empirical allometric associations between variables to predict body size in fossil taxa, with Smith tackling Gigantopithecus and Steudel the fossil hominids.

\section{Clinical exchange}

\section{Robert Walgate}

Harrap's French and English Science Dictionary.

Harrap: 1985. Pp.302. £17.50.

IN 1982, when socialism was the rage again in France, the French became passionate about protecting their language "as a language of science". The then minister of research even established a priority action, a programme mobilisateur, to that end, and launched an ambitious plan for a great new French-language encyclopaedia to embrace all knowledge, as the encyclopaedists of the eighteenth century had done before him. Heady days! The programme and the encyclopaedia project still exist, but somehow the passion has gone. The encyclopaedia has had difficulty finding a publisher. French scientists speak English at international conferences in France, against a ministerial directive. And the preferred language of publication, for anyone wishing to be heard outside F rance, is still English.

Nevertheless a considerable amount of good science still appears only in French for example in the Comptes Rendus - and the publication of a new French-English ○ 1985 Nature Publishing Group
They both advocate what Smith has described as the "narrow" allometric approach, but differ in their attitude towards the advisability of averaging the results of several attempts to estimate size. I side with Smith on this; the average of three poor estimates is not likely to provide a good one.

The remaining contributions include investigations of the influence of size on limb design (Preuschoft and Demes; McNeill Alexander), energetics (Heglund) and polygyny (in which Clutton-Brock rightly criticizes others for offering circular arguments to explain sexual dimorphism and polygyny, and then proceeds to offer another himself!). Bookstein contributes a paper on how to measure shape change and Fleagle furnishes a general review of allometry. Finally, Armstrong provides an excellent review of the relationships, causal or otherwise, between body size and brain size and structure.

Jungers is to be congratulated on his editorial efforts. The 20 contributions necessarily vary in scope, quality and novelty, but are uniform in style and layout, and remarkably free of typographical errors. Altogether this is a suitable volume to mark the coming of age of primate allometry, and it is only three years late to mark the golden jubilee of Huxley's seminal book on relative growth.

Bernard Wood is Courtauld Professor of Anatomy at The Middlesex Hospital Medical School, University of London.

(and English-French) science dictionary is an event of some interest.

However, the readership of the dictionary may be more limited than Harrap's expect. The book includes relatively few technical terms in the physical as opposed to the medical and biological sciences (with their naming of parts, and organisms and maladies), and since the translations of the physical terms are often self-evident (astronomy - astronomie), this dictionary will prove of real help mostly to biologists and clinical scientists. Picking a page at random confirms this impression: out of $\mathbf{5 0}$ definitions nearly half are in biology, zoology or medicine; 15 per cent in physics, chemistry and astronomy; 15 per cent in geology and oceanography; and the rest are general terms. As further examples, the book offers no translation of "hadron" or "lepton", and classifies "neutrino" as a biological term; includes "geode" but not "geoid"; and seems not to have heard of the "magnetosphere" or a "white dwarf". Nevertheless with much French clinical science in particular still published in French, this dictionary will find a role in easing the two-way traffic between English-speaking biologists and clinical scientists and their French counterparts. $\square$

Robert Walgate is European correspondent of Nature. 